\title{
PSA-tests bij mannen ouder dan 74 jaar: zwart-wit of toch een grijs gebied?
}

\author{
Sebastiaan Remmers namens ERSPC Rotterdam Study Group - Renée Hogenhout namens ERSPC Rotterdam \\ Study Group - Monique J. Roobol namens ERSPC Rotterdam Study Group
}

Geaccepteerd op: 25 November 2020 / Published online: 6 January 2021

(C) The Author(s) 2021

Samenvatting Prostaatkankerscreening middels PSA bij mannen > 70-74 jaar wordt afgeraden vanwege overdiagnostiek. In deze studie proberen we te achterhalen of er een subgroep te identificeren is - levensverwachting en kwaliteit van leven in ogenschouw genomen - waarbij screening nog wel zinvol zou kunnen zijn. Geïncludeerd werden mannen van 70-74 jaar die waren ingeloot in de interventiearm van de ERSPC Rotterdam en niet waren gediagnosticeerd met prostaatcarcinoom ten tijde van de screening. In dit artikel worden de incidentie en de mortaliteitsdata beschreven. Uiteindelijk werden 3.040 mannen geïncludeerd. Gedurende een periode van 24 jaar ontwikkelden 202 mannen prostaatkanker (7\%), van wie er 52 (26\%) metastasen kregen en $26 \%$ overleed aan de ziekte. De PSA-waarde ten tijde van screening was voorspellend voor prostaatkankersterfte. De conclusie luidde dat mannen $>74$ jaar niet per definitie moeten worden uitgesloten van prostaatkankerscreening, gezien de kans op metastasen en sterftecijfers. Beoordeling van vitaliteit en counseling over nadelen van screening vormen, samen met PSA-bepaling en verdere risicostratificatie, de sleutel tot zinvolle screening.

Trefwoorden prostaatkankerscreening · prostaatcarcinoom $\cdot$ PSA

Drs. Sebastiaan Remmers en drs. Renée Hogenhout leverden aan dit artikel een gelijkwaardige bijdrage. Zie de appendix voor alle leden van de ERSPC Rotterdam Study group.

drs. S. Remmers · drs. R. Hogenhout .

prof. dr. M. J. Roobol ( $\square)$

Afdeling Urologie, Erasmus MC, Rotterdam, Nederland m.roobol@erasmusmc.nl
PSA based screening in men over the age of 74 years: a black-and-white issue or a grey area?

Abstract Men $>70-74$ years of age are excluded from PSA-based screening for prostate cancer because of overdiagnosis. In this study we will determine if we should apply PSA-based screening in elderly in terms of life expectancy and quality of life. Men aged between 70-74 years randomly assigned in the screening group of the Dutch ERSPC and not diagnosed with prostate cancer at time of screening were included. Incidence and mortality were described. In the end 3,040 men were included. During a follow up of 24 years, 202 (7\%) were diagnosed with prostate cancer of which 52 (26\%) developed metastasis and $26 \%$ died of prostate cancer. PSA at time of screening predicted prostate cancer specific mortality (PCSM). Concluded was that men $>74$ years of age should not be refrained from screening given the risk of metastasis and the mortality rate. Health assessment and counseling together with PSA testing and further risk stratification are the key to a valid screening strategy.

Keywords Prostate cancer screening · Prostate cancer · PSA

\section{Introductie}

Volgens de huidige NVU-, EAU- en AUA-aanbevelingen is prostaatkankerscreening door middel van PSA-bepaling geïndiceerd - na counseling over de mogelijke voor- en nadelen - bij mannen jonger dan 70-75 jaar of wanneer de levensverwachting ten minste 10-15 jaar is [1-3]. Bij oudere mannen wegen de voordelen namelijk vaak niet op tegen de nadelen en potentiële risico's die prostaatkankerscreening met zich meebrengt, door de beperktere levensverwachting en eventuele comorbiditeit [4]. In de European 


\title{
Hier staat een advertentie.
}

\author{
ce bohn \\ stafleu \\ van loghum
}

Houten 2021 


\title{
Hier staat een advertentie.
}

\author{
ce bohn \\ stafleu \\ van loghum
}

Houten 2021 


\title{
Hier staat een advertentie.
}

\author{
ce bohn \\ stafleu \\ van loghum
}

Houten 2021 


\title{
Hier staat een advertentie.
}

\author{
ce bohn \\ stafleu \\ van loghum
}

Houten 2021 
Randomized Study for Sceening for Prostate Cancer (ERSPC) werd geen reductie gezien van prostaatkankergerelateerde sterfte door PSA-screening bij mannen die voor het eerst gescreend werden tussen hun 70e en 74e jaar [5, 6]. De levensverwachting is sinds 1990 echter aanzienlijk toegenomen [7]. In 1990 had een Nederlandse man tussen de 70 en 74 jaar oud een gemiddelde levensverwachting van 12,4 jaar. In 2018 was dit opgelopen naar 14,8 jaar. Deze positieve trend suggereert dat de hedendaagse groep oudere mannen mogelijk wel baat zou kunnen hebben bij prostaatkankerscreening [8].

De vraag of prostaatkankerscreening gerechtvaardigd is in een groep met een over het algemeen aanzienlijke kans op aandoeningen met een concurrerend risico op overlijden, kan ter discussie worden gesteld. Echter, de aanbeveling tegen prostaatkankerscreening in 2008 door de United States Preventive Services Task Force (USPSTF) voor mannen > 75 jaar, leidde tot een stijging in incidentie van gemetastaseerd prostaatkanker $[9,10]$. In dit stadium kunnen patiënten, soms zelfs irreversibele, ernstige klachten ontwikkelen, de palliatieve behandeling is kostbaar en heeft een significante negatieve invloed op de kwaliteit van leven $[11,12]$. De opportunistische screening die ontstaat dan wel toeneemt als reactie op een dergelijk beleid, is bewezen ineffectief gebleken en leidt zelfs tot meer overdiagnostiek [13].

In de Nederlandse arm van de ERSPC werd screening beëindigd wanneer een participant de leeftijd van 74 jaar had bereikt of wanneer hij was gediagnosticeerd met prostaatkanker. Het doel van dit onderzoek is om, met huidige gegevens van de Nederlandse arm van de ERSPC met een lange follow-up, te achterhalen of er wellicht een subgroep te identificeren is in deze leeftijdscategorie waarbij gestructureerde, risicogestratificeerde screening zinvol zou kunnen zijn, niet alleen als het gaat om het terugdringen van sterfte, maar ook als het gaat om behoud van kwaliteit van leven. We zullen hierbij de relatie tussen de PSA-waarde ten tijde van screening, de incidentie van klinischsignificant en gemetastaseerd prostaatkanker na beëindiging van eenmalige screening en prostaatkankersterfte in kaart brengen.

\section{Materiaal en methode}

De ERSPC is een gecontroleerde gerandomiseerde en populatiegebaseerde studie die het effect van PSAscreening op prostaatkankersterfte onderzoekt. De Nederlandse tak van de ERSPC, de ERSPC Rotterdam, begon met randomiseren in december 1993. Indien een deelnemer werd geloot in de interventiearm, kreeg deze tijdens een screeningsronde een PSA-test aangeboden. Indien de PSA-waarde $\geq 3,0 \mathrm{ng} / \mathrm{ml}$ was, werden transrectaal echogeleide (TRUS) biopten afgenomen. Screening (met een interval van 4 jaar) stopte voor een deelnemer zodra deze de leeftijd van 75 jaar had bereikt of indien hij gediagnosticeerd werd met prostaatkanker. Indien een deelnemer met een diagnose van prostaatkanker overleed, werd door middel van een speciaal samengestelde commissie (Cause of Death Committee, CODC) de doodsoorzaak vastgesteld. Of de participant was overleden aan de gevolgen van prostaatkanker werd bepaald met een vaststaand algoritme [14]. In deze studie includeerden we uitsluitend de deelnemers uit de ERSPC die geloot waren in de interventiearm met een leeftijd van 70-74 jaar en eenmalig een screeningsronde ondergingen, welke plaatsvond tussen 1993 en 1999. Mannen die gediagnosticeerd werden met prostaatkanker ten tijde van dit screeningsbezoek werden niet geïncludeerd in de analyses. De diagnoses prostaatkanker die werden gesteld na het beëindigen van screening komen voort uit verrichte diagnostiek vanwege klachten, toevalsbevindingen en opportunistische screening en werden verkregen door koppelingen met het Integraal Kankercentrum Nederland.

\section{Statistische analyses}

Door middel van beschrijvende statistiek werd geïnventariseerd welke mannen na de screening de diagnose prostaatkanker kregen, waarbij we resultaten categoriseerden per PSA-niveau. Tevens werd er gekeken naar het percentage klinisch-significant prostaatkanker gedefinieerd als Gleason-score $\geq 3+4$ (of ISUP Grade Group $\geq 2$ ). Indien er geen Gleason-score bekend was, werd klinisch-significant prostaatkanker gedefinieerd als $\geq \mathrm{cT} 2 \mathrm{~b}$. Door middel van een nested case-control design werd met een conditionele logistische regressieanalyse vastgesteld of de PSA-waarde ten tijde van de screening gerelateerd was aan latere prostaatkankersterfte. In deze analyse werd één deelnemer die was overleden aan prostaatkanker gekoppeld met drie deelnemers die niet aan prostaatkanker waren overleden op basis van dezelfde follow-up. Als laatste werd onderzocht of verdere risicostratificatie mogelijk was op basis van de rol die de Prostaatwijzer (www.prostaatwijzer.nl) mogelijk had gespeeld voor deelnemers met een PSA-waarde $\geq 3,0 \mathrm{ng} / \mathrm{ml}[15$, 16] en voor deelnemers met een PSA-waarde boven de leeftijdsafhankelijke drempelwaarde van $6,5 \mathrm{ng} / \mathrm{ml}$ [17]. Alle analyses werden uitgevoerd met R statistische software, versie 3.5.1.

\section{Resultaten}

In totaal kwamen 3.040 deelnemers in aanmerking voor analyse. In ons cohort hadden 866 (28\%) deelnemers een PSA-waarde boven de afkapwaarde voor biopsie (tab. 1). De mediane PSA-waarde ten tijde van de screening was $1,7 \mathrm{ng} / \mathrm{ml}$ (interquartile range, $\mathrm{IQR}=0,9-3,3)$. Van dit cohort werd de follow-up van maximaal 24 jaar beschreven.

Gedurende de follow-up werden 202 (7\%) deelnemers gediagnosticeerd met prostaatkanker, waarbij in 88 (44\%) gevallen sprake was van klinisch-significant 
Tabel 1 Incidentiecijfers per PSA-categorie

\begin{tabular}{|c|c|c|c|c|c|c|c|}
\hline $\begin{array}{l}\text { PSA bij screening } \\
(\mathrm{ng} / \mathrm{ml})\end{array}$ & $n(\%)$ & $\mathrm{PCa}(\%)$ & $\begin{array}{l}\text { mediane PSA bij } \\
\text { diagnose (IQR) }\end{array}$ & $\begin{array}{l}\text { csPCa }(\% \text { van } \\
\mathrm{PCa} / \% \text { van } n)\end{array}$ & $\begin{array}{l}\mathrm{M}+(\% \text { van } \\
\mathrm{PCa} / \% \text { van } \operatorname{cs} \mathrm{PCa})\end{array}$ & $\begin{array}{l}\text { overleden met PCa- } \\
\text { diagnose ( } \% \text { van } \mathrm{PCa})\end{array}$ & $\begin{array}{l}\text { PCa-sterfte (\% van } \\
\text { overleden met PCa) }\end{array}$ \\
\hline$<1,0$ & $770(25)$ & $11(1)$ & $6,2(1,4-8,0)$ & $5(45 / 1)$ & $3(27 / 20)$ & $11(100)$ & $3(27)$ \\
\hline $1,0-1,9$ & $908(30)$ & $37(4)$ & $15,5(3,9-53,7)$ & $23(62 / 3)$ & $13(35 / 39)$ & $32(86)$ & $8(25)$ \\
\hline $2,0-2,9$ & $496(16)$ & $42(8)$ & $6,9(4,5-21,0)$ & $19(45 / 4)$ & $14(33 / 47)$ & 37 (88) & $12(32)$ \\
\hline $3,0-6,5$ & $608(20)$ & $63(10)$ & $10,5(5,6-24,0)$ & $22(35 / 4)$ & $10(16 / 36)$ & $51(84)$ & $9(18)$ \\
\hline$\geq 6,5$ & $258(8)$ & $49(19)$ & $17,5(10,7-48,3)$ & $19(39 / 7)$ & $12(24 / 32)$ & $45(92)$ & $13(29)$ \\
\hline totaal & 3.040 & $202(7)$ & $11,5(5,4-31,2)$ & $88(44 / 3)$ & $52(26 / 38)$ & $176(87)$ & $45(26)$ \\
\hline
\end{tabular}

prostaatkanker en 52 (26\%) mannen metastasen ontwikkelden. Voor de mannen met prostaatkanker was de mediane tijd tussen het stoppen met screenen (en tevens de studie) en diagnose 6,3 jaar (IQR=3,6-9,9). De mediane tijd tussen de screening en de diagnose van klinisch-significant prostaatkanker was 8,8 jaar (IQR $=4,6-11,6)$. De incidentie van prostaatkanker bij een PSA-waarde $<1,0 \mathrm{ng} / \mathrm{ml}$ was $1 \%$, bij een PSAwaarde tussen de 1,0 en $1,9 \mathrm{ng} / \mathrm{ml} 4 \%$ en bij een PSAwaarde tussen de 2,0 en $2,9 \mathrm{ng} / \mathrm{ml}$ was deze $8 \%$. Van de mannen met prostaatkanker had respectievelijk $45 \%, 62 \%$ en $45 \%$ klinisch-significant prostaatkanker en ontwikkelde respectievelijk $27 \%$, 35\% en $33 \%$ metastasen. Van de deelnemers met een PSA-waarde tussen de 3,0 en $6,5 \mathrm{ng} / \mathrm{ml}$ werd $35 \%$ gediagnosticeerd met klinisch-significant prostaatkanker en $16 \%$ met metastasen. Van de deelnemers met een PSA-waarde $\geq 6,5 \mathrm{ng} / \mathrm{ml}$ ( $n=258$ ) werd $19 \%$ gedurende de beschikbare follow-up gediagnosticeerd met prostaatkanker, waarbij het in $39 \%$ van de gevallen om klinisch-significant prostaatkanker ging. In deze groep kregen 12 mannen $(24 \%$ van de mannen met de diagnose prostaatkanker) gemetastaseerde ziekte, van wie $50 \%$ op het moment van de diagnose klinisch-significant prostaatkanker had.

Van alle deelnemers overleed $85 \%$ op een mediane leeftijd van 83,4 jaar (IQR=78,9-87,6). Van de deelnemers die waren gediagnosticeerd met prostaatkanker overleden er 176 (87\%), van wie $26 \%$ daadwerkelijk overleed aan prostaatkanker binnen een mediane tijd na diagnose van 5,3 jaar (IQR=2,2-10,0). Van de deelnemers met een PSA $\geq 6,5 \mathrm{ng} / \mathrm{ml}$ die waren gediagnosticeerd met prostaatkanker had $29 \%$ een letale uitkomst. Uit de nested case-control-analyse bleek dat de PSA-waarde op het moment van de screening voorspellend was voor prostaatkankersterfte met een odds ratio van $1,16(95 \%-\mathrm{BI}=1,06-1,26 ; p=0,001)$. Dit betekent dat per unit toename van de PSA-waarde ten tijde van de screening de kans op een diagnose van iedere vorm van prostaatkanker met $16 \%$ toeneemt, ofwel: een deelnemer met een PSA van $4,0 \mathrm{ng} / \mathrm{ml}$ ten tijde van de screeningsronde heeft $16 \%$ meer kans om te overlijden aan prostaatkanker dan een deelnemer met een PSA van 3,0 ng/ml.

Bij de groep mannen met een PSA-waarde boven de $3,0 \mathrm{ng} / \mathrm{ml}$ bleek uit verdere risicostratificatie met behulp van de Prostaatwijzer het discriminerend vermogen voor klinisch-significant prostaatkanker $70 \%$ te zijn. Indien deze Prostaatwijzer gebruikt zou worden met de klinische gegevens ten tijde van screening, kunnen we, met een sensitiviteit van $90 \%$ op het vinden van klinisch-significant prostaatkanker, $21 \%$ van alle biopsieprocedures voorkomen. Bij de mannen met een PSA-waarde boven de leeftijdsafhankelijke drempelwaarde van $6,5 \mathrm{ng} / \mathrm{ml}$ bleek het discriminerend vermogen $84 \%$ te zijn. In deze groep zou, bij een afkapwaarde van $4 \%$, geen van de klinisch-significant prostaatkankers gemist worden en $31 \%$ van de biopten voorkomen worden.

\section{Discussie}

In deze studie hebben we onderzocht of er een subgroep te identificeren is van mannen die ouder zijn dan 74 jaar ten tijde van screening, die mogelijk wel baat zou kunnen hebben bij het continueren van prostaatkankerscreening middels PSA-bepaling. De analyses zijn gebaseerd op een groep mannen tussen de 70 en 74 jaar die tijdens hun eerste en tevens laatste populatiegebaseerde screeningsronde niet zijn gediagnosticeerd met prostaatkanker. Eventuele PSAbepalingen na screening zijn over het algemeen uitgevoerd door de huisarts. Bij een verhoogde PSAwaarde en/of urologische klachten, bestaat er volgens de huidige Nederlandse richtlijn de mogelijkheid tot verwijzing naar de uroloog voor verdere diagnostiek. Volgens Kerkhof et al. liet $24 \%$ van de deelnemers in de controlegroep van de ERSPC na randomisatie zijn PSA-waarde bepalen [18]. Van de 3.040 geïncludeerde mannen, bij wie prostaatkankerscreening na hun $74 \mathrm{e}$ levensjaar werd beëindigd, werd $7 \%$ in een later stadium alsnog gediagnosticeerd met prostaatkanker. De mediane tijd tussen de laatste screening en de diagnose prostaatkanker is in deze groep 6,3 jaar (IQR=3,6-9,9). In de huidige studie heeft, van de mannen die zijn gediagnosticeerd met prostaatkanker, $44 \%$ klinisch-significant prostaatkanker en ontwikkelt $26 \%$ metastasen. Van alle mannen met prostaatkanker die op dit moment zijn overleden, is $26 \%$ ook daadwerkelijk overleden aan de ziekte. Dit betekent dat, wanneer de EAU- en de AUA-richtlijn worden gehandhaafd, en er dus geen prostaatkankerscreening 
meer wordt verricht na de leeftijd van 70-74 jaar [1, 2], op basis van onze data, bij 1 op de 14 van deze mannen de diagnose prostaatkanker niet wordt gesteld, terwijl dit in bijna de helft van de gevallen klinischsignificant prostaatkanker zou betreffen en een kwart van deze mannen daadwerkelijk zou metastaseren en overlijden aan de ziekte. Kanttekening bij deze getallen is dat het absolute risico op prostaatkanker, al dan niet het risico op klinisch-significant prostaatkanker en gerelateerde sterfte, uiteraard wel laag is. Des te belangrijker in de overweging om ook de groep oudere mannen gestructureerde, risicogestratificeerde prostaatkankerscreening aan te bieden, is niet alleen het terugdringen van sterfte, maar ook het behoud van kwaliteit van leven van deze mannen. Nadat prostaatkankerscreening bij mannen $\geq 75$ jaar in 2008 werd afgeraden door de USPSTF, steeg in de periode van 2010-2016 de incidentie van gemetastaseerd prostaatkanker met 5,2\% per jaar [9]. Klinische problemen die bij mannen met een gemetastaseerd stadium van de ziekte kunnen optreden met een aanzienlijke negatieve invloed op de kwaliteit van leven, zijn pijnlijke botmetastasen waarvoor palliatieve bestraling nodig kan zijn, pathologische fracturen die soms zelfs leiden tot een dwarslaesie, afvloedbelemmering van de nier(en) en/of blaas waarvoor soms drainage nodig is, en anemie waarvoor bloedtransfusie nodig kan zijn [11, 12]. Daarnaast kan de hormonale behandeling gepaard gaan met hinderlijke bijwerkingen en leidt deze behandeling tot een verhoogd risico op cardiovasculaire events en metabole veranderingen $[3,11]$.

Daarnaast zal, wanneer de oudere groep mannen wordt uitgesloten van georganiseerde screening, niet alleen het aantal mannen toenemen die zich initieel presenteert met gemetastaseerde ziekte, maar zal na verwachting ook de overdiagnostiek alleen maar toenemen ten gevolge van ineffectieve, opportunistische screening. Godtman et al. toonden namelijk in het historisch cohort van de Göteborg Screening Study aan dat met deze screeningswijze het aantal mannen dat moet worden gediagnosticeerd om één prostaatkankergerelateerd sterftegeval te voorkomen bijna twee keer zo hoog is in vergelijking met georganiseerde screening [13]. Deze overdiagnostiek zal wederom niet ten goede komen aan de kwaliteit van leven.

Opvallend was de hoge mediane leeftijd van overlijden van 83,4 jaar. Een mogelijke verklaring hiervoor is healthy screening bias, waarbij een gescreende populatie in het algemeen een langere levensverwachting heeft dan de algemene populatie door een hoger gezondheidsbewustzijn [19, 20]. Door de toegenomen levensverwachting en toegenomen levenskwaliteit [21] is het mogelijk dat de gescreende ERSPC-populatie van 1993-1999 nu meer representatief is voor de huidige populatie.

Een andere belangrijke bevinding binnen onze studie was dat de PSA-waarde op moment van screening voorspellend bleek voor prostaatkankersterfte met een odds ratio van 1,16. De PSA-waarde kan dus, alhoewel de relatie niet erg sterk is, in deze groep wel gebruikt worden als screeningsinstrument. Wel opvallend was dat bij de mannen met prostaatkanker de incidentie van klinisch-significante prostaatkanker bij een lage PSA-waarde vergelijkbaar of zelfs wat hoger was dan bij de mannen met een verhoogde PSA-waarde. Een mogelijke verklaring hiervoor is dat hooggradig prostaatcarcinoom soms slecht gedifferentieerd kan zijn en daarmee weinig PSA produceert [22]. Deze significante prostaatkankers worden dus met deze manier van screenen gemist of op een later tijdstip wellicht alsnog gediagnosticeerd. Vanwege de lage specificiteit van de PSA-waarde, maar ook om onderdiagnostiek te beperken, zijn er verschillende instrumenten voor risicostratificatie in ontwikkeling waarvan sommige zelfs al worden toegepast in de kliniek. De PRECISION (Prostate Evaluation for Clinically Important Disease: Sampling Using Image Guidance or Not?) trial bijvoorbeeld, toonde aan dat een negatieve MRI voor prostaatkanker resulteerde in een reductie van $28 \%$ van de prostaatbiopsieprocedures in een klinisch cohort [23]. Ook de Prostaatwijzer (www.prostaatwijzer.nl) wordt in de hedendaagse klinische praktijk toegepast om het risico op prostaatkanker in kaart te brengen door middel van meerdere voorspellers naast de PSA-waarde, namelijk eventuele negatieve uitkomst van eerdere biopsieprocedures, rectaal toucher, volume van de prostaat en eventueel de Prostate health index (Phi) [15, 16, 24]. De Prostaatwijzer is recentelijk uitgebreid met implementatie van resultaten die voortkomen uit de MRI-scan van de prostaat [25].

Het is echter niet aannemelijk dat de baten van het screenen van alle mannen na een leeftijd 70-74 jaar opweegt tegen de schade van het screenen. Alle geïncludeerde mannen met een PSA-waarde van $3,0 \mathrm{ng} / \mathrm{ml}$ of hoger kregen prostaatbiopten aangeboden. Bij verdere risicostratificatie van deze groep met de Prostaatwijzer kon met een sensitiviteit van $90 \%$ op het vinden van klinisch-significant prostaatkanker, $21 \%$ van alle biopten worden voorkomen. Op basis van de PSA-waarde, gemeten tijdens screening, is het mogelijk om een hoogrisicogroep te identificeren, namelijk de mannen met een PSA-waarde boven de leeftijdsafhankelijke drempelwaarde van $6,5 \mathrm{ng} / \mathrm{ml}$ (zie tab. 1). Wanneer we in deze groep de Prostaatwijzer toepassen, zien we een verder discriminerend vermogen van $84 \%$ voor klinisch-significant prostaatkanker waarbij zelfs $31 \%$ van de biopsieprocedures achterwege kan worden gelaten zonder dat significante prostaatkankers gemist worden.

Ondanks deze verfijning van risicostratificatie moet ook deze groep oudere mannen goed geïnformeerd worden over de nadelen en potentiële risico's van screening zoals overdiagnostiek en het ondergaan van belastende biopsieprocedure(s) met bijkomende complicaties. Sepsis is zo'n ernstige complicatie waarbij de incidentie - met in de literatuur erg uiteenlopende getallen van 0 tot $6 \%$ [26] - niet erg hoog is, 
maar waarvan de afloop, zeker bij ouderen, fataal kan zijn en daarom niet onbesproken mag blijven. Belangrijke kanttekening hierbij is dat niet alleen de leeftijd, maar ook de conditie bepalend lijkt te zijn voor het beloop en de uitkomst van sepsis [27]. Alhoewel de EAU-richtlijn nog geen biopsietechniek superieur acht, gaan wel steeds meer klinieken over op de transperineale route als alternatief voor de transrectale route, omdat bij deze methode mogelijk het risico op sepsis kleiner is $[1,28]$. Een ander nadeel van screening is dat het vinden van prostaatkanker soms onnodige interventies met zich meebrengt, die voortvloeien uit onder andere angst voor progressie van laaggradige ziekte. Uit de langetermijnfollowup van de Prostate Cancer Research International Active Surveillance (PRIAS)-studie blijkt dat uiteindelijk $18 \%$ van de patiënten actieve behandeling ondergaat van laagrisico-prostaatkanker, niet op basis van progressie maar vanwege angst, op eigen verzoek of om andere redenen [29]. Deze aanzienlijke groep wordt hiermee blootgesteld aan de neveneffecten van bestraling of radicale prostatectomie, zoals radiatieproctitis en/of -cystitis, incontinentie en impotentie. Zonder screening hadden zij zeer waarschijnlijk nooit kennisgenomen van de prostaatkanker en daarmee geen hinder ondervonden van hun latente ziekte.

Om in te schatten of iemand de potentiële risico's en eventueel benodigde behandeling fysiek aankan, is het belangrijk niet alleen leeftijd als maatstaaf te gebruiken. Everaerts et al. beargumenteren dat bij alle mannen $>70$ jaar aan de hand van een geriatrische beoordeling onderscheid gemaakt dient te worden tussen vitale en kwetsbare ouderen, waarbij een oude, maar vitale man standaard curatieve behandeling aangeboden zou moeten krijgen [30]. Een dergelijke beoordeling wordt in de dagelijkse klinische praktijk immers bij iedere en dus ook jongere patiënt uitgevoerd aan de hand van een performance status, die een bewezen prognostisch waarde heeft voor overleving [31]. De bijdrage van deze inschatting van de 'biologische leeftijd' bij het bepalen van het verdere beleid wordt alleen maar groter, gezien de toenemende levensverwachting. De leeftijd waarop beperkingen als gevolg van ouderdom optreden en de levensverwachting zijn namelijk in gelijke mate toegenomen [21]. Met andere woorden, mensen blijven op steeds hogere leeftijd nog vitaal. We krijgen dus te maken met een groep oudere mannen die langer, in goede conditie, leeft en die momenteel nog wordt uitgesloten van screening. Bovendien is in 1990 besloten om mannen in de leeftijdscategorie 65-69 jaar met een levensverwachting van gemiddeld 13,4 jaar wel te screenen [8]. De groep mannen van 70-74 jaar heeft inmiddels deze levensverwachting ingehaald met 1,4 jaar. Dit is een belangrijk gegeven in de overweging om ook oudere mannen prostaatkankerscreening aan te gaan bieden.

Deze studie kent een aantal beperkingen. De incidentie van prostaatkanker die is gediagnosticeerd na het beëindigen van screening komt voort uit PSAbepaling of klachten waarvoor de huisarts de patiënt doorverwees naar de uroloog. In zo'n situatie werd voor de PSA-bepaling geen protocol gevolgd, wat leidt tot een niet-eenduidig beleid. Een deel van de deelnemers zullen op eigen verzoek de PSA-waarde hebben laten vervolgen; een ander deel niet. Hierdoor weten we niet welk deel van de diagnoses voortkomt uit alsnog verrichte screening, wat het lastig maakt om in te schatten of het continueren van screening in deze groep zinvol is. Verder is voorzichtigheid geboden met het generaliseren van onze resultaten naar andere landen waar de levensverwachting van mannen mogelijk lager ligt. Alhoewel ook hierbij weer geldt dat niet alleen gekeken moet worden naar leeftijd, maar ook naar performance status, waarbij het gaat om de beoordeling of iemand vitaal genoeg is voor de eventueel uit screening voortkomende diagnostiek en behandeling.

Een van de sterke punten van deze studie is de lange follow-up, die in het Nederlandse cohort van de ERSPC startte in 1992 en waaruit tot op heden nog steeds data worden geëxtraheerd. Verder wordt de oorzaak van overlijden van iedere met prostaatkanker gediagnosticeerde deelnemer bepaald door een toegewijde commissie (CODC). Deze commissie beoordeelt het complete medische dossier van deze deelnemers. In deze beoordeling wordt niet alleen informatie over progressie van ziekte of eventueel opgetreden metastasen meegenomen, maar ook comorbiditeit.

\section{Conclusie}

De resultaten uit onze studie suggereren dat mannen ouder dan 74 jaar niet per definitie moeten worden uitgesloten van prostaatkankerscreening op basis van het leeftijdscriterium. Alhoewel het absolute risico laag is, ontwikkelt een kwart van de mannen die nadien nog wordt gediagnosticeerd met prostaatkanker metastasen en sterft ook een kwart daadwerkelijk aan de ziekte. Het stoppen van screening in deze groep mannen kan dus leiden tot onderdiagnostiek en onderbehandeling in een steeds ouder en fitter wordende Nederlandse populatie met een negatieve invloed op kwaliteit van leven. Desalniettemin blijft het wel of niet screenen van mannen boven de 74 jaar een grijs gebied: beoordeling van de vitaliteit en counseling over de nadelen van prostaatkankerscreening vormen, samen met een PSA-bepaling en eventueel verdere risicostratificatie, de sleutel tot zinvolle screening.

Open Access This article is distributed under the terms of the Creative Commons Attribution 4.0 International License (http://creativecommons.org/licenses/by/4.0/), which permits unrestricted use, distribution, and reproduction in any medium, provided you give appropriate credit to the original author(s) and the source, provide a link to the Creative Commons license, and indicate if changes were made. 


\section{Appendix}

Erasmus Medical Centre, Departments of Urology, Clinical Chemistry, Pathology, Public Health and statistics Netherlands (CBS)

dr. W.J. Kirkels, uroloog; COD commissie

dr. J.B.W. Rietbergen, uroloog

dr. I.W. van der Cruijsen, uroloog

dr. R. Raaijmakers, uroloog

dr. S.H. de Vries, uroloog

dr. S. Roemeling, uroloog

dr. C. Gosselaar, huisarts

dr. T. Wolters, uroloog

dr. R.C.N. van den Bergh, uroloog

dr. P.J. van Leeuwen, uroloog

dr. M. Bul, uroloog

dr. X. Zhu, uroloog

dr. H.A. van Vugt, postdoctoraal onderzoeker

dr. L.P. Bokhorst, radiotherapeut in opleiding

dr. A.R. Alberts, uroloog in opleiding

drs. F.-J. Drost, huisarts in opleiding

dr. J.F.M. Verbeek, radioloog in opleiding

drs. D. Osses, promovendus

drs. H. Luiting, promovendus

drs. S. Remmers, statisticus

drs. R. Hogenhout, promovendus

drs. J.W. Salman, huisarts

dr. L.D.F. Venderbos, universitair docent

drs. G. Yurdakul, uroloog

drs. A. Boeken-Kruger, uroloog

drs. C. Wijburg, uroloog

drs. M. Forouzanfor, uroloog

drs. M. de Boer, uroloog

dr. R. Postma, patholoog

dr. A.N. Vis, uroloog

dr. R. Hoedemaeker, patholoog

dr. A. van Leenders, patholoog

dr. B. Blijenberg, klinisch chemicus

dr. R.H. van Schaik, klinisch chemicus

dr. P.J. van der Maas, epidemioloog

dr. S. Otto, epidemioloog

dr. G. Draisma, statisticus

dr. P. Beemsterboer, epidemioloog

dr. M. Essink-Bot, epidemioloog

dr. I. Korfage, epidemioloog

dr. R. Boer, ict-specialist/wiskundige

dr. M. Wildhagen, statisticus

drs. W. Merkelbach, COD-commissie

dr. W. Hoekstra, COD-commissie

dr. J. Blom, COD-commissie

dr. C.H. Bangma, COD-commissie

dr. T. Lock, COD-commissie

dr. A. Noordzij, COD-commissie

drs. R.A.M. Damhuis, epidemioloog, kankerregistratie

drs. A. Reedijk, epidemioloog, kankerregistratie

dr. R. Kranse, statisticus, kankerregistratie

D.W. Roobol, databeheer

W. Roobol, websitebeheer
E. van den Berg, secretaresse

G.-J. de Zwart, echografist

C.G.A.M. Franken-Raab, databeheer

M. van Slooten-Midderig, databeheer

A. Smit, medisch assistent

V. van der Drift, databeheer

E. de Bilde, databeheer

L. Mani, medisch assistent

M. Visser-van Dongen, databeheer

H. Versteeg-Leenheer, databeheer

B. Zoutendijk, databeheer

N. Vink, databeheer

H. van Meurs, echografist

M. den Rooijen, databeheer

\section{Literatuur}

1. Mottet N, BellmuntJ, Briers E, Bolla M, Bourke L, Cornford P. EAU - ESTRO -ESUR - SIOG guidelines on prostate cancer. EAU Annual Congress Amsterdam 2020. Arnhem: EAU Guidelines Office; 2020.

2. Carter HB, Peter CA, Michael JB, et al. Early detection of prostate cancer: AUA Guideline. JUrol. 2013;190(2):419-26.

3. Saylor PJ, Smith MR. Metabolic complications of androgen deprivation therapy for prostate cancer. J Urol. 2009;181(5):1998-2006. discussie 2007-1998.

4. Walter LC, Bertenthal D, Lindquist K, Konety BR. PSA screening among elderlymen withlimitedlife expectancies. JAMA. 2006;296(19):2336-42.

5. Schröder FH, Hugosson J, Roobol MJ, et al. Screening and prostate-cancer mortality in a randomized European study. NEngJ Med. 2009;360(13):1320-8.

6. Hugosson J, Roobol MJ, Mansson M, et al. A 16-yr follow-up of the European randomized study of screening for prostate cancer. Eur Urol. 2019;76(1):43-51.

7. Wang H, Dwyer-Lindgren L, Lofgren KT, et al. Age-specific and sex-specific mortality in 187 countries, 1970-2010: a systematic analysis for the global burden of disease study 2010. Lancet. 2012;380(9859):2071-94.

8. CBS. Levensverwachting; geslacht, leeftijd (per jaar en periode van vijf jaren) [Life expectancy; gender, age (per year and period of five years)] 2019 [updated 2019-05-17]. Beschikbaarvia: https://opendata.cbs.nl/statline/\#/CBS/nl/ dataset/37360ned/table?fromstatweb. Geraadpleegd op 20 maart 2020.

9. Jemal A, Culp MB, Ma J, Islami F, Fedewa SA. Prostate cancer incidence 5 years after US preventive services task force recommendations against screening. J Natl Cancer Inst. 2020; https://doi.org/10.1093/jnci/djaa068.

10. Broderick JM. CDC warns incidence of metastatic prostate cancer on the rise. Urology Times. 2020. https:// www.urologytimes.com/view/cdc-warns-incidence- ofmetastatic-prostate-cancer-on-the-rise. Geraadpleegd op: 28 okt 2020.

11. Haar RW ter, Boevé LMS, Hillenius JJ, Andel G van. Het klinisch beloop bij gemetastaseerd prostaatcarcinoom. Tijdschr Urol. 2019;9:131-44.

12. Holm M, Doveson S, Lindqvist O, Wennman-Larsen A, Fransson P. Quality of life in men with metastatic prostate cancer in their finalyears before death-a retrospective analysis of prospective data. BMCPalliat Care. 2018;17(1):126.

13. Arnsrud Godtman R, Holmberg E, Lilja H, Stranne J, Hugosson J. Opportunistic testing versus organized prostatespecific antigen screening: outcome after 18 years in the 
Göteborg randomized population-based prostate cancer screening trial. Eur Urol. 2015;68(3):354-60.

14. Koning HJD, Blom J, Merkelbach JW, et al. Determining the cause of death in randomized screening trial(s) for prostate cancer. BJU Int. 2003;92(s2):71-8.

15. Roobol MJ, Vugt HA van, Loeb S, et al. Prediction of prostate cancer risk: the role of prostate volume and digital rectal examination in the ERSPC risk calculators. Eur Urol. 2012;61(3):577-83.

16. Roobol MJ, Steyerberg EW, Kranse R, et al. A risk-based strategy improves prostate-specific antigen-driven detection of prostate cancer. Eur Urol. 2010;57(1):79-85.

17. Oesterling JE, Jacobsen SJ, Chute CG, et al. Serum prostatespecific antigen in a community-based population of healthy men. Establishment of age-specific reference ranges. JAMA. 1993;270(7):860-4.

18. Kerkhof M, Roobol MJ, Cuzick J, et al. Effect of the correction for noncompliance and contamination on the estimated reduction of metastatic prostate cancer within a randomized screening trial (ERSPC section Rotterdam). Int JCancer. 2010;127(11):2639-44.

19. Otto SJ, Schroder FH, Koning HJ de. Low all-cause mortality in the volunteer-based Rotterdam section of the European randomised study of screening for prostate cancer: selfselection bias? J Med Screen. 2004;11(2):89-92.

20. Vis AN, Roemeling S, Reedijk AM, Otto SJ, Schroder FH. Overall survival in the intervention arm of a randomized controlled screening trial for prostate cancer compared with a clinically diagnosed cohort. Eur Urol. 2008;53(1): 91-8.

21. Westendorp RG, Schalkwijk FH. When longevity meets vitality. Proc Nutr Soc. 2014;73(3):407-12.

22. Mahal BA, Aizer AA, Efstathiou JA, Nguyen PL. Association of very low prostate-specific antigen levels with increased cancer-specific death in men with high-grade prostate cancer. Cancer. 2016;122(1):78-83.
23. Kasivisvanathan V, Rannikko AS, Borghi M, et al. MRItargeted or standard biopsy for prostate-cancer diagnosis. NEngJ Med. 2018;378(19):1767-77.

24. Roobol MJ, Vedder MM, Nieboer D, etal. Comparison of two prostate cancer risk calculators that include the prostate health index. Eur Urol Focus. 2015;1(2):185-90.

25. Alberts AR, Roobol MJ, Verbeek JFM, et al. Prediction of high-grade prostate cancer following multiparametric magnetic resonance imaging: improving the Rotterdam European randomized study of screening for prostate cancer risk calculators. Eur Urol. 2019;75(2):310-8.

26. Loeb S, Vellekoop A, Ahmed HU, et al. Systematic review of complications of prostate biopsy. Eur Urol. 2013;64(6):876-92.

27. Banerjee D, Opal SM. Age, exercise, and the outcome of sepsis. Crit Care. 2017;21(1):286.

28. Chang DT, Challacombe B, Lawrentschuk N. Transperineal biopsy of the prostate - is this the future? Nat Rev Urol. 2013;10(12):690-702.

29. Drost FH, Rannikko A, Valdagni R, et al. Can active surveillance really reduce the harms of overdiagnosing prostate cancer? A reflection of real life clinical practice in the PRIAS study. Transl Androl Urol. 2018;7(1):98-105.

30. Everaerts W, Rij S van, Reeves F, Costello A. Radical treatment of localised prostate cancer in the elderly. BJU Int. 2015;116(6):847-52.

31. Mor V, Laliberte L, Morris JN, Wiemann M. The Karnofsky Performance Status Scale. An examination of its reliability and validity in a research setting. Cancer. 1984;53(9):2002-7.

drs. Sebastiaan Remmers, statisticus

drs. Renée Hogenhout, arts-onderzoeker

prof. dr. Monique J. Roobol, hoogleraar Besliskunde in de urologie 